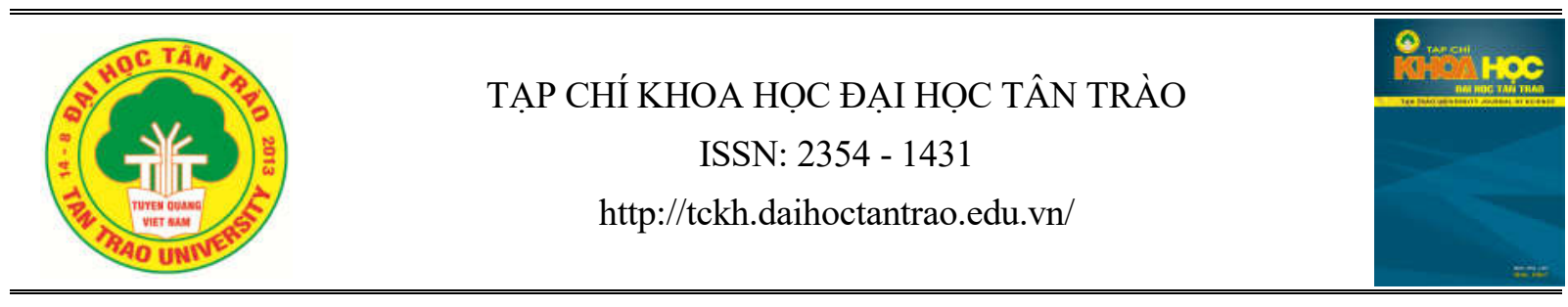

\title{
Thực trạng sử dụng ngôn ngũ dân tộc thiểu số trên đài phát thanh, truyền hình khu vực miền Trung - Tây Nguyên
}

\author{
Cao Thị Hảo ${ }^{a *}$ \\ ${ }^{a}$ Trưòng Đại học Su phạm - Đại học Thái Nguyên \\ EEmail: caohaokv@gmail.com
}

Thông tin bài viết

Ngày nhận bài:

14/11/2018

Ngày duyệt đăng:

$10 / 12 / 2018$

\section{Tì khoá:}

Ngôn ngũ dân tộc thiểu số; quốc gia đa dân tộc; cộng đồng dân tộc thiểu số.

\section{Tóm tắt}

Việt Nam là một nước đa dân tộc nên vấn đề sử dụng ngôn ngữ dân tộc thiểu số để truyền thông đặc biệt là trên phát thanh, truyền hình sẽ mang một ý nghĩa quan trọng. Bài viết đề cập đến vấn đề sử dụng ngôn ngữ dân tộc thiểu số trên đài phát thanh, truyền hình ở các tỉnh miền Trung - Tây Nguyên của Việt Nam. Các chương trình phát thanh, truyền hình bằng tiếng dân tộc thiểu số của các đài trung ương và địa phương ở khu vực miền Trung - Tây Nguyên đã có một vị trí và vai trò quan trọng trong đời sống xã hội của bà con dân tộc thiểu số. Nó vừa thông tin được những chính sách của Đảng và Nhà nước đến đồng bào đồng thời cũng là nơi lưu giữ và truyền tải ngôn ngữ và văn hoá của các cộng đồng dân tộc thiểu số.

\section{1. Đặt vấn đề}

Việt Nam là một nước đa dân tộc nên vấn đề sử dụng ngôn ngữ dân tộc thiểu số trên phát thanh, truyền hình - một phương tiện truyền thông công phổ biến, sẽ mang một ý nghĩa quan trọng. Các nhà nghiên cứu trên thế giới cũng đánh giá cao vai trò của truyền thông bằng ngôn ngữ dân tộc thiểu số. Matsaganis cho rằng: "Hoạt động truyền thông bằng ngôn ngữ dân tộc thiểu số giúp gắn kết các cộng đồng dân tộc thiểu số, bảo tồn ngôn ngữ, văn hóa và giúp các thành viên của cộng đồng dân tộc thiểu số hội nhập tốt hơn vào đời sống xã hội” (1).

Điều này càng thực sự thiết thực ở những địa phương có đông đồng bào dân tộc thiểu số sinh sống. Các tỉnh miền Trung - Tây Nguyên của Việt Nam, tiêu biểu như: Quảng Ngãi, Quảng Trị, Gia Lai, Đắc Lắc, Kon Tum, Ninh Thuận, Lâm Đồng, Thừa Thiên

\footnotetext{
1 Matsaganis, M. và các cộng sự (2010), Understanding Ethnic Media: Producers, Consumers, and Societies, SAGE Publications.
}

Huế... là nơi tập trung nhiều bà con dân tộc thiểu số như Cor, Hrê, Ja rai, Ba na, Ê đê, M’nông, Xơ đăng, Giẻ - Triêng, Chăm, Cơ ho, Chu ru, Pa Cô... Đây là vùng đất đa dân tộc, đa văn hóa, nơi cư trú của hơn 47 dân tộc anh em với rất nhiều đặc trưng, sắc thái riêng. Nơi đây, chương trình phát thanh, truyền hình bằng tiếng dân tộc của các đài trung ương và địa phương đã có một vị trí và vai trò quan trọng trong đời sống xã hội. Bởi, trong bối cảnh bùng nổ thông tin như hiện nay, hệ thống phát thanh, truyền hình là trung tâm cung cấp thông tin đầy đủ và liên tục, phản ánh các vấn đề nóng hổi, cập nhật sự kiện liên tục và trở thành một phương tiện thông tin hữu hiệu khó có loại hình báo chí nào thay thế được ở những vùng sâu, vùng xa khi vấn đề giao lưu văn hoá còn nhiều trở ngại, khó khăn.

Đồng bào dân tộc thiểu số nói chung thường sinh sống ở các địa bàn vùng núi cao, vùng sâu, vùng xa có địa hình hiểm trở, khó khăn cho việc đi lại. Đời sống vật chất thiếu thốn, đời sống tinh thần nghèo 
nàn, trình độ dân trí thấp, ít được tiếp cận với các phương tiện truyền thông. Lợi dụng những khó khăn về nhiều mặt của đồng bào dân tộc thiểu số, các thế lực phản động thường xuyên dụ dỗ lôi kéo đồng bào vào ý đồ phản động của chúng nhằm chia rẽ khối đại đoàn kết dân tộc, chia rẽ cộng đồng người dân tộc thiểu số; gây nghi ngờ đường lối đổi mới của Đảng. Trong bối cảnh đó, việc cho ra đời các chương trình phát thanh, truyền hình bằng tiếng dân tộc thiểu số tại mỗi tỉnh miền núi, vùng sâu, vùng xa là cần thiết hơn bao giờ hết. Các chương trình phát thanh, truyền hình tiếng dân tộc bản địa đã khơi dậy và phát huy cao độ niềm tự hào chính đáng của đồng bào dân tộc thiểu số. Khi đồng bào nghe nội dung tuyên truyền bằng chính ngôn ngữ của mình thì đồng bào sẽ hiểu, đồng bào tin thì sẽ có sức cuốn hút, thúc giục hành động, tạo nên sức mạnh trong cộng đồng, góp phần phát triển kinh tế - xã hội, xoá đói giảm nghèo, tăng cường khối đại đoàn kết dân tộc, chống lại âm mưu "Diễn biến hòa bình" của các thế lực thù địch, giữ vững sự ổn định, an ninh chính trị và trật tự xã hội trên địa bàn. Điều này đã từng được nhiều nhà nghiên cứu về truyền thông dân tộc trên thế giới thừa nhận. Theo Cormack trong bài viết Hoạt động truyền thông bằng ngôn ngữ các dân tộc thiểu số ở Tây Âu (Minority language media in Western Europe) in trên tạp chí Truyền thông châu Âu (European Journal of Communication) số 13 năm 1998: "Vì hoạt động truyền thông bằng ngôn ngữ dân tộc thiểu số có vai trò quan trọng trong việc góp phần đảm bảo an ninh chính trị, chủ quyền quốc gia, lợi ích đất nước nên khi xem xét tới hoạt động truyền thông bằng ngôn ngữ dân tộc thiểu số, yếu tố chính trị của quốc gia cần phải được đưa lên vị trí hàng đầu bên cạnh những nhu cầu về thưởng thức văn hóa và giải trí" (2).

2. Thực trạng sử dụng ngôn ngữ dân tộc thiểu số trên đài Phát thanh - Truyền hình ở các tỉnh miền Trung - Tây Nguyên

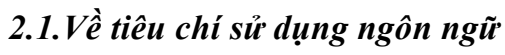

Như đã nói ở trên, khu vực miền Trung - Tây Nguyên nói chung là địa bàn có rất đông các tộc người cùng sinh sống đan xen, các cộng đồng dân cư tuy thuộc nhiều nhóm ngôn ngữ khác nhau nhưng cơ

\footnotetext{
${ }^{2}$ Cormack, M. (1998), Minority language media in Western Europe: Preliminary considerations, European Journal of Communication 13.
}

bản có sự hòa hợp, đoàn kết, không phân biệt giữa người tại chỗ và người nơi khác đến. Trong bối cảnh cư trú đan xen như hiện nay, hoạt động phát thanh, truyền hình vùng dân tộc thiểu số thường căn cứ vào một số tiêu chí: cộng đồng có ảnh hưởng lớn và thường là có vai trò là trung tâm chính trị, kinh tế, văn hóa... của cộng đồng. Ngôn ngữ đó có số người dùng nhiều. Đây là cách làm giảm thiểu được số chương trình cùng một thứ tiếng ở nhiều đài thuộc một vùng. Cơ hội tập trung nguồn lực con người và tài chính cho chương trình về một thứ tiếng dân tộc dùng chung cho cả vùng sẽ tăng cao và cùng với đó, chất lượng chương trình tiếng dân tộc cho bà con sẽ tăng khả năng thuyết phục. Tuy nhiên, phát thanh, truyền hình cũng hướng tới những cộng đồng cần chú ý tuyên truyền giáo dục về chính trị, kinh tế, văn hóa, quốc phòng, an ninh; cần được cố kết cộng đồng và cũng đã chú ý tới cả những ngôn ngữ của cộng đồng có chữ viết.

Hiện nay, ở miền Trung - Tây Nguyên, ngôn ngữ của các dân tộc thiểu số có số dân đông (trên 100.000 người), sống tập trung, như các dân tộc Gia Rai, $\hat{E}$ Đê, Ba Na, Chăm, Xơ Đăng, Hrê, Cơ Ho, Raglai,...đều được sử dụng trên sóng phát thanh và truyền hình. Thậm chí, ngôn ngữ của các dân tộc chưa đến 100.000 người như các dân tộc Mnông, Giẻ-Triêng, Bru Vân Kiều, Cơ Tu, Pa Cô,... cũng được sử dụng trên sóng phát thanh và truyền hình (Đắc Lắc, Đắc Nông, Kon Tum, Quảng Trị và Thừa Thiên Huế). Có những chương trình phát sóng của một số đài Phát thanh - Truyền hình trước đây với thời lượng chỉ 15 phút hoặc 30 phút/ngày, thì nay đã tăng lên 30 phút hoặc 60 phút/ngày như các Đài Phát thanh - Truyền hình Quảng Trị, Thừa Thiên Huế, Kon Tum, Bình Thuận, Quảng Ngãi,.. Có những đài Phát thanh - Truyền hình trước đây chỉ mới phát sóng một thứ tiếng dân tộc thì nay đã phát sóng hai, ba tiếng dân tộc như các Đài Phát thanh - Truyền hình Đắc Lắc, Kon Tum, Phú Yên,...

\subsection{Vî̀ số lự̛̣ng ngôn ngũ đự̛c sử dụng}

Qua khảo sát, chúng tôi đã thống kê được số lượng ngôn ngữ dân tộc thiểu số sử dụng trên Đài Phát thanh - Truyền hình của 11 tỉnh thuộc khu vực miền Trung - Tây Nguyên là 16 ngôn ngữ. 
Bảng thống kê ngôn ngũ dân tộc thiểu số trên đài phát thanh, truyền hình các tỉnh Miền Trung - Tây Nguyên

\begin{tabular}{|c|c|c|c|c|c|}
\hline \multirow[b]{2}{*}{$\begin{array}{l}\text { ST } \\
\text { T }\end{array}$} & \multirow[b]{2}{*}{$\begin{array}{l}\text { Ngôn } \\
\text { ngữ }\end{array}$} & \multicolumn{2}{|c|}{ Đài tīnh } & \multicolumn{2}{|c|}{ Đài trung ương } \\
\hline & & Phát thanh & $\begin{array}{l}\text { Truyền } \\
\text { hình }\end{array}$ & $\begin{array}{c}\text { vov } \\
\text { khu } \\
\text { vưc } \\
\text { Tây } \\
\text { Nguyên }\end{array}$ & $\begin{array}{c}\text { vTV 5 } \\
\text { khu } \\
\text { vự } \\
\text { Tây } \\
\text { Nguyên }\end{array}$ \\
\hline 1 & $\mathrm{BaNa}$ & $\begin{array}{l}\text { Kon Tum } \\
\text { Gia Lai } \\
\text { Phú Yên }\end{array}$ & $\begin{array}{l}\text { Kon Tum } \\
\text { Gia Lai } \\
\text { Phú Yên }\end{array}$ & $\mathrm{x}$ & $\mathrm{x}$ \\
\hline 2 & $\begin{array}{l}\text { Bru Vân } \\
\text { Kiều }\end{array}$ & & Quảng Trị & & \\
\hline 3 & Ca Dong & QuảngNam & QuảngNam & & \\
\hline 4 & Cor & QuảngNgãi & QuảngNgãi & & \\
\hline 5 & $\mathrm{Co} \mathrm{Ho}$ & Lâm Đồng & Lâm Đồng & $\mathrm{x}$ & $\mathrm{x}$ \\
\hline 6 & $\mathrm{Co} \mathrm{Tu}$ & $\begin{array}{l}\text { Thừa Thiên } \\
\text { Huể } \\
\text { Quảng Nam }\end{array}$ & $\begin{array}{l}\text { Thừa Thiên } \\
\text { Huế } \\
\text { Quảng Nam }\end{array}$ & & \\
\hline 7 & Chăm & $\begin{array}{l}\text { Bình Thuận } \\
\text { Ninh Thuận } \\
\text { Phú Yên }\end{array}$ & $\begin{array}{l}\text { Binh Thuận } \\
\text { Ninh Thuận } \\
\text { Phú Yên }\end{array}$ & & \\
\hline 8 & $\mathrm{ChuRu}$ & LâmĐồng & LâmĐồng & & $\mathrm{x}$ \\
\hline 9 & $\hat{\mathrm{E}}$ đê & $\begin{array}{l}\text { Đắk Lắc } \\
\text { Phú Yên }\end{array}$ & $\begin{array}{l}\text { Đắk Lắc } \\
\text { Phú Yên }\end{array}$ & $\mathrm{x}$ & $\mathrm{x}$ \\
\hline 10 & Gia rai & $\begin{array}{l}\text { Đắk Lắc } \\
\text { Kon Tum } \\
\text { Gia Lai }\end{array}$ & $\begin{array}{l}\text { Đắk Lắc } \\
\text { Kon Tum } \\
\text { Gia Lai }\end{array}$ & $\mathrm{x}$ & $\mathrm{x}$ \\
\hline 11 & $\begin{array}{l}\text { Giè - } \\
\text { Triêng }\end{array}$ & Kon Tum & Kom Tum & & $\mathrm{x}$ \\
\hline 12 & Hrê & QuảngNgãi & QuảngNgãi & & \\
\hline 13 & Mnong & $\begin{array}{l}\text { ĐắkNông } \\
\text { Đắk Lằc }\end{array}$ & $\begin{array}{l}\text { Đắk Nông } \\
\text { Đắk Lằc }\end{array}$ & $\mathrm{x}$ & $\mathrm{x}$ \\
\hline 14 & $\begin{array}{l}\text { Pa Cô (Tà } \\
\text { Öi) }\end{array}$ & $\begin{array}{l}\text { Thừa Thiên } \\
\text { Huê }\end{array}$ & $\begin{array}{l}\text { Thừa Thiên } \\
\text { Huế }\end{array}$ & & \\
\hline 15 & Raglay & $\begin{array}{l}\text { Khánh Hoà } \\
\text { Ninh Thuận }\end{array}$ & $\begin{array}{l}\text { Khánh Hoà } \\
\text { Ninh Thuận }\end{array}$ & & \\
\hline 16 & Xơ Đăng & Kon Tum & Kom Tum & $\mathrm{x}$ & $\mathrm{x}$ \\
\hline
\end{tabular}

Nhìn vào bảng thống kê trên, chúng ta thấy, Đài Trung ương phát 9 ngôn ngữ, trong đó, Đài tiếng nói Việt Nam VOV khu vực Tây Nguyên phát 6 ngôn ngữ: Gia rai, M'nông, Ba Na, Xơ đăng, Ê đê, Cơ Ho; Đài truyền hình VTV5 khu vực Tây Nguyên phát 8 ngôn ngữ: Gia Rai, Mnong, Ba Na, Xơ Đăng, Giẻ Triêng, Chu Ru, Cơ Ho, Ê Đê. Các đài địa phương ngoài bắt sóng đài Trung ương đều tự sản xuất chương trình của mình. Trong khảo sát của chúng tôi, chỉ có duy nhất Đài Phát thanh - Truyền hình Quảng Trị có truyền hình tiếng Bru Vân Kiều nhưng không có phát thanh ngôn ngữ này, còn lại 15 ngôn ngữ đều đã được lên sóng phát thanh và truyền hình các tỉnh miền Trung - Tây Nguyên. Ba ngôn ngũ̃: Ba na, Chăm, Gia rai được phát thanh và truyền hình ở ba tỉnh. Bốn ngôn ngữ: Cơ Tu, Ê đê, M'nông, Raglai được phát thanh và truyền hình ở hai tỉnh. Còn lại 08 ngôn ngữ: Ca Dong, Cor, Cơ Ho, Chu Ru, Giẻ Triêng, Hrê, Pa Cô, Xơ đăng chỉ có phát thanh và truyền hình ở một tỉnh.

\subsection{Về cách thức sử dụng ngôn ngũ}

Trong quá trình biên dịch, làm tin, bài, các đài thường chú trọng vấn đề viết ngắn gọn, dễ hiểu, tránh cách viết dài dòng, hay là dùng những từ hoa mỹ để diễn đạt nhằm truyền đạt hiệu quả tới bà con dân tộc nghe và xem. Bởi vậy, khi dịch từ văn bản tiếng phổ thông sang tiếng dân tộc thiểu số, các biên tập viên không dịch sát nghĩa theo từng từ, mà bám ý nhằm dịch bật được nội dung cần truyền tải tới bà con. Dịch như thế nào phải phù hợp với lối nói chuyện của bà con, đúng với cấu trúc ngữ pháp của tiếng dân tộc đó. Chẳng hạn, với tiếng Cơ Ho từ Lúa nước không dịch là Kòi dà (theo tiếng Cơ Ho Lúa là Kòi, Nước là Dà), mà dịch thành Kòi sre sẽ phù hợp với cách nói của người $\mathrm{Cơ} H o$, vì từ sre của tiếng $\mathrm{Cơ}$ Ho dịch sang tiếng Việt chính là ruộng).

Trong tiếng Chăm, tiền tố ngữ (langlikuk) có vị trí rất quan trọng trong việc tạo từ, phân biệt từ này với từ kia. Ví dụ chỉ là một từ đơn như: "la" đứng một mình thì không có nghĩa. Nhưng nếu thêm tiền tố ngữ vào đằng trước từ "la" thì nó sẽ tạo ra nhiều từ có nghĩa khác nhau. $\mathrm{Vd}$ nhu: ula - con rắn; alabên dưới, hala- lá cây, kala- đại diện... Do vậy trong cách phát âm của tiếng Chăm thường phát âm rõ chuẩn những tiền tố ngữ này để tạo từ và phân biệt rõ ngữ nghĩa của câu. Tuy nhiên thực tế hiện nay ở trong cộng đồng người Chăm, người ta quen sử dụng câu tỉnh lược, từ tỉnh lược. Dùng trong những trường hợp đối đáp, giữa 2 người sẽ hiểu họ đang nói đến vấn đề gì, vật gì. Ví dụ: hadip - pathang nghĩa là vợchồng. Thế nhưng trong cách nói dân gian, người ta chỉ phát âm ra chữ "dip" - "thang", mà bỏ qua tiền tố ngữ tạo nghĩa của chữ. Lâu dần hình thành nên những từ giản tiết mà nếu chung ta lại thêm tiền tố ngữ khi phát âm thì thành ra khá xa lạ với cách nói hiện đại.

Khác với tiếng Việt, tiếng Gia Rai không có dạng câu bị động nên khi dịch tiếng Việt qua tiếng Gia Rai mà gặp những câu bị động thì cần phải chuyển sang câu chủ động trước khi dịch, ví dụ: Em được cô giáo khen - Cô giáo khen em - Nai bơni kơ kâo; Bài quốc ca do Nhạc sĩ Văn Cao sáng tác - Nhạc sĩ Văn Cao sáng tác bài quốc ca: Pô pơceh Văn Cao pơceh tơlơi adôh lon ia.

Không chỉ ở cấu trúc ngữ pháp hay từ vựng, mà đôi khi yếu tố văn hoá bản địa cũng chi phối tới cách 
sử dụng từ ngữ trong ngôn ngữ dân tộc thiểu số. Ví dụ trong chương trình tiếng Cor không dùng các từ: ánh tiêu, rấp tố, rấp tiêu trong chương trình tiếng Hrê không dùng các từ lô cành, té... Đó là những từ nói tục của đồng bào Hrê và Cor. Trong phát âm ngôn ngữ tiếng dân tộc Hrê và Cor cũng cần chú ý đọc cho chính xác, nếu không chính xác thì bà con dễ hiểu nhầm, ví dụ như tiếng Hrê đọc: "Am ba cui mới mang" có nghĩa là "Cho anh xin ngủ được không". Câu trên nếu đọc chệch âm là "Am ba cối mới mang" thì nghĩa của từ sẽ khác, dễ bị hiểu nhầm trong sinh hoạt. Đối với ngôn ngữ tiếng Cor cách phát âm cũng rất khó. Người dân ở vùng đường nước gần sông suối phát âm khác với người dân đường rừng. Do đó, phát thanh viên cần tìm hiểu phát âm sao cho cả người đường nước và người đường rừng đều hiểu.

Trong tiếng $\mathrm{Pa}$ Cô, chủ thể và khách thể trực tiếp đối thoại xưng hô ở ngôi 1 và ngôi 2 , ví dụ: kư (tôi, ở ngôi 1 , chủ thể) và măi (mày, ở ngôi hai, khách thể) dẫu quan hệ giữa chủ thể và khách thể là cha - con, mẹ - con, ông bà - cháu chắt, chú - cháu, chị - em, anh - em, bạn bè cùng trang lứa...thì ngôn từ vẫn không thay đổi. Điều này khác với tiếng Việt. Người Việt sử dụng đại từ xưng hô rõ ràng, rạch ròi trong từng mối quan hệ khi giao tiếp.

Ví dụ:

$\begin{array}{lll} & \text { Tiếng Pa Cô } & \text { Tiếng Việt } \\ \text { Mẹ: } & \text { Kư lăng măi (Tao yêu mày) } & \text { Mẹ: } \quad \text { Mệu con. } \\ \text { Con: } & \text { Kư lăng măi (Tao yêu mày) } & \text { Con: } \quad \text { Con yêu mẹ. }\end{array}$

Chính vì vậy, khi sử dụng ngôn ngữ Pa Cô trên sóng phát thanh, truyền hình, biên dịch viên phải chú ý chuyển tải sao cho bà con hiểu đúng nghĩa của từ.

Trên thực tế sử dụng ngôn ngữ dân tộc trên đài phát thanh, truyền hình, có một số từ, ngữ mới được du nhập hiện nay như các danh từ: tivi, radio... hay các từ chỉ chức danh về mặt chính quyền, tên riêng các cơ quan doanh nghiệp vẫn đang là đề tài thảo luận khi thể hiện trên sóng truyền hình. Có ý kiến cho rằng, cần giữ nguyên cách phát âm những tên riêng, những danh từ trên theo cách phát âm phổ thông tiếng Việt. Nhưng, một số chức danh vẫn có thể dịch ra được bằng tiếng dân tộc như: bí thư, chủ tịch, hiệu trưởng, giám đốc... Do vậy, cần có một quá trình để người nghe, người xem làm quen và dần tiếp nhận.

\section{Một số vấn đề đặt ra nhằm cải tạo thực trạng}

Ở hầu hết các dân tộc thiểu số ở miền Trung và Tây Nguyên, thực tế đời sống làm nảy sinh yêu cầu sử dụng tiếng Việt ngày càng ở phạm vi rộng hơn, đa dạng hơn và ở mức độ sâu sắc hơn. Ngược lại, tiếng nói riêng của các dân tộc thiểu số hiện đang đứng trước nguy cơ bị lãng quên hoặc pha trộn đến mức nhiều khi mất cả nét bản sắc, bị giảm thiểu các chức năng xã hội, chỉ được dùng trong một số hoàn cảnh giao tiếp nhất định ở gia đình và làng xóm, chủ yếu chỉ người lớn tuổi sử dụng và chỉ ở dạng khẩu ngữ (không ở dạng ngôn ngữ thành văn với sự tham gia của chữ viết...), trở nên nghèo nàn và kém dần sức biểu cảm do không được bảo tồn và phát triển. Do đó, cần chú trọng và có kế hoạch cụ thể về vấn đề dạy tiếng nói, chữ viết cho đồng bào dân tộc thiểu số trong các trường Tiểu học, Trung học cơ sở, các trường Phổ thông dân tộc nội trú ở các vùng có đông đồng bào dân tộc thiểu số sinh sống. Thế hệ trẻ ở đây cần phải được nghe, nói, đọc, viết thành thạo tiếng nói, chữ viết của dân tộc mình nhằm nâng cao kiến thức và hiểu biết để lưu giữ văn hóa ngôn ngữ, chữ viết cho các tộc người. Ngoài ra, các tỉnh cũng cần chú ý mở lớp dạy tiếng nói, chữ viết cho cán bộ, công chức để tạo điều kiện cho quá trình công tác khi tiếp xúc làm việc với đồng bào được thuận lợi hơn. Hiện nay vấn đề trên đã được triển khai ở các tỉnh nhưng chất lượng thực hiện chưa tốt, nhất là vấn đề chuẩn hoá tài liệu học tập. Đây cũng là một yếu tố quan trọng để góp phần nâng cao chất lượng, hiệu quả của hoạt động phát thanh, truyền hình bằng ngôn ngữ dân tộc thiểu số.

Có một thực tế là nhiều khán thính giả cho biết họ không hiểu hoặc hiểu không hết khi nghe hoặc xem chương trình phát bằng tiếng dân tộc mình. Điều này liên quan đến vấn đề sử dụng phương ngữ. Cần lựa chọn phương ngữ nào trên sóng phát thanh, truyền hình để đồng bào nghe, xem hiểu được cũng là một vấn đề. Ở khu vực miền Trung - Tây Nguyên, tôn giáo có vai trò rất quan trọng và tác động mạnh tới vấn đề sử dụng ngôn ngữ dân tộc thiểu số. Nhà thờ, với việc sử dụng các ngôn ngữ dân tộc thiểu số để truyền đạo, với các bản dịch Kinh thánh, những lời giảng đạo, thánh ca, và cả những câu chuyện mang màu sắc hư ảo cổ tích về Chúa Cứu thế hay Đức Allah đã góp phần khiến các ngôn ngữ được sử dụng tích cực, trở nên phong phú về từ vựng và cách diễn đạt. Nhiều ngôn ngữ còn giữ được và phát triển được trong đồng bào chính là do người dân đến nhà thờ đọc kinh thánh. Chúng ta có thể kể đến các trường hợp tiếng: Gia Rai, Ê Đê, Xơ Đăng, Ba Na... Do đó, khi sử dụng ngôn ngữ trên các Đài Phát thanh - Truyền hình, chúng ta cần chú ý vốn từ ngữ được sử dụng trong tôn giáo. 
Hiện nay vấn đề nhân sự thực hiện chương trình phát thanh, truyền hình bằng ngôn ngữ dân tộc thiểu số đang là một khó khăn lớn đối với hầu hết các đài ở khu vực miền Trung - Tây Nguyên. Về mặt số lượng, nhân sự thực hiện chương trình này rất ít, chưa đáp ứng đủ yêu cầu, có những đài chỉ có 1 hoặc 2 nhân sự (Đài Phát thanh - Truyền hình Thừa Thiên Huế), thậm chí có những đài chỉ có duy nhất một phát thanh viên tiếng dân tộc (Đài Phát thanh - Truyền hình Quảng Ngãi). Về chất lượng, đa số các biên tập viên, phát thanh viên là người đồng bào ở các địa phương và đang sử dụng tiếng dân tộc nên trong cách dịch, đọc các tin bài trong chương trình phát sóng sẽ gần gũi với bà con mình hơn, có thể giúp bà con tiếp nhận thông tin nhanh và chính xác, sát với thực tế. Nhưng mặt khác, những nhân sự này lại chưa được đào tạo bài bản, chính quy, còn hạn chế về nghiệp vụ. Do đó cần có những chính sách phù hợp để cải thiện tình trạng nhân sự vừa thiếu, vừa yếu nhằm nâng cao hiệu quả của phát thanh, truyền hình bằng ngôn ngữ dân tộc thiểu số ở các đài địa phương khu vực miền Trung Tây Nguyên.

Trên thế giới, một số nhà nghiên cứu như Gillian Doyle, Marshall McLuhan lo lắng về hiệu quả bảo tồn các ngôn ngữ dân tộc thiểu số trong hoạt động truyền thông. Họ chỉ ra rằng, hiện nay, tại nhiều quốc gia ở châu Âu, các chương trình truyền hình thực hiện theo nguyên tắc lợi nhuận nên các đài truyền hình châu Âu thường dành thời lượng phát sóng và tài trợ nhiều cho các chương trình bằng ngôn ngữ quốc gia (state language) hoặc bằng ngôn ngữ các dân tộc chiếm thành phần dân cư đa số. Nguyên nhân này khiến việc sản xuất các sản phẩm truyền thông bằng ngôn ngữ dân tộc thiểu số bị hạn chế ${ }^{(3)}$. Rõ ràng, tính thương mại hoá và môi trường xã hội hiện đại cũng là một rào cản đối với vấn đề phát triển truyền thông bằng ngôn ngữ dân tộc thiểu số. Do đó, các Đài Phát thanh - Truyền hình cần có kế hoạch để nâng cao chất lượng tin, bài, hấp dẫn người nghe, xem và giúp họ gắn bó với ngôn ngữ và văn hoá của dân tộc mình; chú trọng thời lượng phát sóng và chất lượng phủ sóng đến các vùng miền để đồng bào có thể tiếp cận nghe, xem.

Qua việc khảo sát bước đầu về thực trạng sử dụng ngôn ngữ dân tộc thiểu số trên các đài phát thanh, truyền hình ở khu vực miền Trung - Tây Nguyên, chúng tôi thấy đa số các đài cả trung ương và địa phương đã bước đầu quan tâm đến việc thực hiện chương trình, cách thức sử dụng ngôn ngữ sao cho đạt hiệu quả cao, tuy nhiên, chất lượng sử dụng ngôn ngữ ở các chương trình còn cần phải nâng cấp hơn nữa. Bên cạnh đó, hiện nay chủ yếu các chương trình tiếng dân tộc chỉ phát trên sóng phát thanh, truyền hình và báo in, còn báo mạng thì chưa phổ biến. Hy vọng, trong tương lai, những loại hình truyền thông phát thanh, truyền hình không chỉ phát triển và có chất lượng tốt mà các báo in, báo mạng bằng ngôn ngữ dân tộc thiểu số cần được phổ biến và phát huy hiệu quả nhằm góp phần vào việc phát triển đời sống của người dân tộc thiểu số vì trong xu thế hội nhập chúng ta càng phải giữ gìn ngôn ngữ của dân tộc mình cho thế hệ đi sau không chỉ là bằng ngôn ngữ nói mà còn bằng ngôn ngữ viết.

\section{TÀI LIỆ THAM KHẢO}

1. Ka Pou Diễm (2018), "Một số kinh nghiệm trong quá trình thưc hiện phát thanh, truyền hình bằng tiếng Co Ho", Kỉ yếu Hội thảo Quốc gia: Hoạt động truyền thông bằng ngôn ngữ dân tộc thiểu số khu vực miền Trung - Tây Nguyên, Thừa Thiên Huế, tháng 5/2018, Tr.71-77.

2. Trần Đình Quang (2018), "Một số vấn đề về thưc trạng sản xuất, phát sóng chuoong trình phát thanh, truyền hình tiếng dân tộc ở Quảng Ngãi”, Kỉ yếu Hội thảo Quốc gia: Hoạt động truyền thông bằng ngôn ngữ dân tộc thiểu số khu vực miền Trung - Tây Nguyên, Thừa Thiên Huế, tháng 5/2018, Tr.130-133.

3. Nguyễn Thị Sửu (2018), "Đặc điểm ngôn ngũ $P a$ Cô trong phát thanh, truyền hình các cấp ở khu vục miền Trung - Tây Nguyên", Kỉ yếu Hội thảo Quốc gia: Hoạt động truyền thông bằng ngôn ngữ dân tộc thiểu số khu vực miền Trung - Tây Nguyên, Thừa Thiên Huế, tháng 5/2018, Tr.134-145.

4. Tạ Văn Thông (2018), "Một số vấn đề đặt ra trong phát thanh, truyền hình bằng ngôn ngũ các dân tộc thiểu số ở miền Trung - Tây Nguyên", Kỉ yếu Hội thảo Quốc gia: Hoạt động truyền thông bằng ngôn ngữ dân tộc thiểu số khu vực miền Trung - Tây Nguyên, Thừa Thiên Huế, tháng 5/2018, Tr.63-70.

5. Matsaganis, M. và các cộng sự (2010), Understanding Ethnic Media: Producers, Consumers, and Societies, SAGE Publications.

6. Cormack, M. (1998), Minority language media in Western Europe: Preliminary considerations, European Journal of Communication 13.

7. Doyle, G. (2002), Understanding Media Economics. London: Sage. 
Current situation of using ethnic minority languages on radio and television stations in the Central - Highlands region

Cao Thi Hao

\section{Article info}

Recieved:

14/11/2018

Accepted:

10/12/2018

Keywords:

Ethnic minorities

language; multi-ethnic

countr; ethnic minority

communities.

\begin{abstract}
Vietnam is a multi-ethnic country, so the use of ethnic minority languages for communication, especially on radio and television, will have an important meaning. The article addresses the issue of using ethnic minority languages on radio and television stations in the Central - Highlands provinces of Vietnam. Radio and television programs in ethnic minority languages prove their position and play an important role in the social life of ethnic people in the Central Highlands provinces of Vietnam. They not only propagandize the policies of the Party and the State to its compatriots but also serve as a place of storing and conveying the language and culture of ethnic minority communities.
\end{abstract}

